\title{
Business impact analysis for business continuity: Evidence from Romanian enterprises on critical functions
}

\author{
Carmen PĂUNESCU \\ The Bucharest University of Economic Studies, UNESCO Department for Business \\ Administration, Bucharest, Romania \\ carmen.paunescu@ase.ro \\ Mihaela Cornelia POPESCU \\ The Bucharest University of Economic Studies, Doctoral School for Business \\ Administration, Bucharest, Romania \\ Laura BLID \\ The Bucharest University of Economic Studies, Doctoral School for Business \\ Administration, Bucharest, Romania
}

\begin{abstract}
Organizations are increasingly subject to hazardous events and threats, which can be critical for their business operations and performance. Any natural, accidental, or deliberate incidents that happen to the organization can cause major disruptions to it. The present paper aims to examine the prerequisites for a sound business impact analysis necessary to build the organization's business continuity management capability and ensure business resilience. It is meant to discover those critical functions and resources which are vital to business operations in a sample of small and medium-sized enterprises from a certain geographic area in Romania, in order to maintain their core operations and ensure business continuation. The research results rely on the data collected through face-to-face interviews from 119 Romanian companies. The research findings of the multiple linear regression employed indicate that, in undertaking business impact analysis for business continuity, it is vital for enterprises to identify the skills and level of expertise required from staff to carry out organization's critical activities. Also it is critical for companies to identify alternative premises and systems and means of voice and data communication, as well as the priority suppliers/partners whom they depend on, necessary to undertake their critical activities. The study contributes to the literature by providing empirical evidence on the prerequisites of the organization's business impact analysis that are critical to build a strong business continuity management capability. It also offers new insights to companies meant to generate a better understanding of current practices of undertaking a business impact analysis for business continuation in their organizations.
\end{abstract}

Keywords: business impact analysis, critical functions and resources, business continuity management, ISO 22301, Romanian companies.

Please cite the article as follows: Păunescu, C., Popescu, M.C. and Blid, L. (2018), "Business impact analysis for business continuity: Evidence from Romanian enterprises on critical functions", Management \& Marketing. Challenges for the Knowledge Society, Vol. 13, No. 3 pp. 1035-1050, DOI: 10.2478/mmcks-2018-0021. 


\section{Introduction}

Nowadays, organizations, across all private, public administration or nongovernmental sectors, are increasingly subject to incidents and disruptions, which can severely affect their operations and performance. Accidental disruptions like losing a key employee or core data, a cyber-attack, a supply chain failure, or natural disasters like flooding or earthquake can happen at any moment to any organization. Organizations are also faced with increasing challenges regarding the management of those disruptions in the event of a crisis or after disaster. In order that organizations become more successful in responding to a complex, uncertain and full of risks and threats business environment, they are progressively considering to develop and build a business continuity management (BCM) plan. Business continuity management refers to identification and management of those critical processes and functions of the organization that it can't afford to lose to preserve its core business operations (Giacchero et al. 2013). A business continuity management plan helps organizations to cope with difficult situations, so they can continue to function with as little disruption as possible. Business continuity planning requires attention of many stakeholders within the organization due to the wide range of disruptions which can impact the organization operations and performance.

A business continuity management system demands the organizations to identify their key strategic vulnerabilities, priorities, critical resources and functions, and ensure that they have plans in place to manage, maintain and, in the event of a crisis, recover so that the business can continue without or with minimal disruption (Mcilwee, 2013). The critical functions primarily refer to identification and documentation of organization's key products and services, the critical activities and resources required to deliver these (such as staff, premises, supplies, and technology and data communication), and the impact that a disruption of these activities can have on the organization (ISO 22301: 2012). Any incident, large or small, whether it is natural, accidental or deliberate, can cause major disruption to the organization. As per Fischbacher-Smith (2017), BCM is a "holistic process that deals with a range of task demands generated by disturbances across the range of activities undertaken by the organization" (p. 90). It covers all organizational functions and considers all types of disruptions and the extent to which this BCM is effective is influenced by the wider assessment of organizational performance. Therefore, building organizational resilience, which involves dealing with risks and threats with the purpose of protecting critical assets (physical, intangible, environmental and human), becomes an issue of major importance for both public and private actors, who have shown increased interest in a more secure environment and in an enhanced capacity of handling disruptions (Hollnagel et al., 2006).

Despite the increased organizational awareness of business continuity management, its adoption and dissemination amongst organizations, BCM practitioners and academics still found at an incipient level. This would suggest that it can be done more for organizations to support them with developing and building business continuity capability. Also, the concept of business continuity management has only recently emerged with regard to small and medium sized companies, particularly in Romania, and only few relevant studies were conducted (Speight, 2011; Păunescu, 2017; Kato and Charoenrat, 2018). 
The main goal of the current paper is to examine the prerequisites for a sound business impact analysis in the organization necessary to build its business continuity management and to ensure that this is maintained. This will be accomplished by understanding and examining the role played by the business impact analysis (BIA) for building business continuity capability in Romanian small and medium-sized companies located in a particular geographic area of the country. The present study contributes to the literature by providing empirical evidence on the critical prerequisites of the organization's business impact analysis for building business continuity and ensuring organization's resilience. It also contributes to generating a better understanding of current practices of BCM and BIA by small enterprises in Romania.

\section{Literature review}

What is business continuity management and why does an enterprise need it?

In the present days, large business communities or important supply chain management processes are affected by disruptions caused by unexpected natural events or man-made disasters. These crisis events can be classified in technological failures caused by cyber-attacks, natural events like earthquakes, flooding, tsunami or forest fires, and deliberate disasters caused by terrorist attacks (Zeng and Zio, 2017). To cope with these disruptions large companies develop business impact and risk analysis programs included in a business continuity management plan.

Business continuity is defined by Tucker (2015) as the management of a sustainable process that identifies the critical functions of an organization and develops strategies to continue these functions without or with minimal interruption. By planning in advance how to manage a disruption, rather than waiting for it to happen, the organization will be able to get back to business in the quickest possible time. Any delays could lead to losing valuable business to competitors, or losing customers' confidence in the organization. The ISO 22301 international standard gives a broader definition of BCM as "holistic management process that identifies potential threats to an organization and the impacts to business operations that those threats, if realized, might cause, which provides a framework for building organizational resilience with the capability of an effective response that safeguards the interests of its key holders, reputation, brand and value-creating activities" (ISO 22301:2012, p. 5). By having a business continuity management in place the organization demonstrates the ability to continue its business activities at a basic level after the disaster happened, relying on emergency operations and recovery processes (Cerullo and Cerullo, 2004). According to Zeng and Zio (2017), the continuity measures of the BCM must be divided in four categories, such as: preventive measures, mitigation measures which come into action when the first ones fail, emergency actions when the prior measures could not face the disaster, and recovery activities for re-establishing the business' normality. Mitigation and emergency actions usually determine the degradation level of the business' performance, in case of a disaster or an unexpected event.

Baba et al. (2013) introduce the area business continuity plan (BCP) as a framework of risk management and recovery plan, dedicated to different stakeholders, including small and medium enterprises, supply chain managers, 
regional authorities or administrators and large corporations, who must cooperate in the whole process of business continuation. The purpose of area BCP is to ensure proper impact estimation and risk sharing, effective measures, recovery actions and monitoring activities (Baba et al., 2014). Compiling an area BCP requires following certain steps, starting with analysis of the local risks and vulnerabilities, establishing the frequency of occurrence of certain disruptive events, and estimating the business' local resources and resilience capacities. The next step should be allocated to simulating different scenarios and underlining continuity business problems arisen due to the unexpected event. In the development of the BCP the joint effort needs to be concentrated on protection and restoration measures referring to important infrastructure activities such as transportation, electricity and water supply or communication networks (Maruya, and Torayashiki, 2017). A study conducted by Ota (2011) reveals the importance of cooperation and common effort along the supply chain during the unexpected disaster, which might contribute to a faster recovery and restoration of the core businesses.

Literature refers rather sporadically to disaster management process within small and medium-sized companies. There is a general opinion amongst scholars confirming that small and medium companies are characterized by low level of preparation concerning business continuity in case of disruptive events, lacking in disaster risk management plan or BCP (Păunescu, 2017; Kato and Charoenrat, 2018) According to a study conducted by Charoenrat and Harvie (2014), large organizations are efficient and well prepared to introduce business continuity measures, therefore are more resilient than small or medium enterprises. However, the study reveals the significant role of SMEs in supply chain along with suppliers endorsed by high technologies and good positioning on the market.

Asnar and Giorgini (2008) propose the analysis of business continuity management from a socio-technical perspective, using the time dependency and recovery model, through which the business continuity plan was developed starting with the process of assessing the interdependency among assets and risks associated with business objectives. The analysis is divided in two paths, naming as treatment analysis that considers all sets of measure to mitigate risks, and cost-benefit analysis with the main purpose of identifying the cost-effective measures for reducing the losses at the minimum possible. A similar quantitative model of business continuity and risk analysis is proposed by Tan and Takakuwa (2011) who use a simulation model to analyze the consequences and risks associated with a pandemic disease in a factory.

Other scholars (Zeng and Zio, 2017) propose in their research a loss-based continuity metrics, starting from the idea that business performance and continuity is indirect related to losses produced by a disruptive event. The scholars take into consideration the direct losses (produced during the event) and indirect losses (produced during the recovery process) and define the business continuity value as $\mathrm{BCV}=1-\mathrm{L}_{\mathrm{t}} / \mathrm{L}_{\mathrm{tol}}\left(\mathrm{L}_{\mathrm{t}}\right.$ - total loss, $\mathrm{L}_{\mathrm{tol}}$ - maximum loss that a company can support). When the BCV is less than 0 , the business continuity is seriously affected, approaching to business failure.

Overall, business continuity management assumes a clear understanding of the organization characteristics, resources and risks, selecting the right strategies, 
developing business continuity plans and testing and evaluating plans (Speight, 2011). Baba et al. (2014) argue that the key principles that sustain a reliable business continuity management planning of an enterprise refer to proper organization, protective and mitigation measures, sharing information with its stakeholders, backup investments, employee training and education and risk transfer. Therefore, the importance of business continuity management resides its objective of ensuring enterprise's health and continuity in case of any disruptive event.

\section{Understanding the business impact analysis for business continuity}

The key elements of developing a business continuity management, from which the whole process starts, are undertaking business impact analysis and risk assessment. In the paper we refer only to the first element. Business impact analysis focuses on establishing the critical processes and activities of the enterprise, including the critical resources required to deliver organization's key products and services, with the purpose of understanding the specific of the consequences in case of a disruptive event. Business impact analysis precedes the BCP development and BCM strategy selection and is followed by recovery strategies, plan development, validation, maintenance and training. A business impact analysis also estimates the possible damages that an enterprise might suffer, in terms of delivering its products and services to the customers, without taking into consideration the recovery methods (Bjerga and Aven, 2016). Moreover, it identifies and evaluates the potential effects (financial, safety, regulatory, contractual, image, reputation and so forth) that the disruption can cause to the business operations.

A survey conducted in Thailand in the period 2002-2012, reveals that $47.8 \%$ of SMEs questioned had suffered business' losses as consequences of disaster' occurrences (Kato and Charoenrat, 2018). The results also confirm that $61.7 \%$ of the enterprises surveyed had no business continuity plans. The most important reasons for which the companies fail to intensify the risk management and to define a rigorous business continuity plan, were "lack of knowledgeable personnel/ experts" (46.5\%), "lack of understanding" (34.9\%), "no necessity" (32.6\%) and "lack of tools" (15.1\%); "lack of financial resources" accounted only 15.1\%. Although, 33.3\% from the companies surveyed experienced disruptive events in the past, there is a quite significant percentage (32.6\%) of companies with no awareness regarding the importance of developing BCM and therefore to compile a reliable BCP. The results imply also the positive correlation between the number of employees, amount of assets, and number of years that a company functions with the business continuity management (Kato and Charoenrat, 2018). Based on this argument we develop our first hypothesis as follows:

$H_{1}$ : There is a statistically significant correlation between staff number, staffing level and skills required to undertake organization's critical activities and the business impact analysis.

A reliable business continuity management cannot be implemented unless the business impact analysis reveals all possible worse scenarios in case of a disruptive incident, which could prevent enterprises to maintain core business operations. Faertes's (2015) study emphasizes the importance of risk assessment, human reliability techniques, accessibility to financial resources, operational infrastructure, 
physical resources and social capital as significant tools in preventive, mitigation and recovery of losses included in business continuity practices. In the same spirit, Tracey et al. (2017) consider that the risks-based approach shall be balanced by asset-based approach, for better prevention and recovery measures, moving the focus to strengths of the organizations which sustain resilience and business continuation. Among those organization's strengths they are pointing out categories like human resources, information and communication, location and operational infrastructure and physical resources. Therefore, our second research hypothesis is formulated as follows:

$H_{2}$ : There is a statistically significant correlation between premises, where the products are processed/manufactured/stored, including the manufacturing equipment used, and the business impact analysis.

As risks and threats are inevitable it became more wisely to invest in strengthening the resilience of an enterprise than dissipate resources in trying to control the environment or fighting some risks (Wildavsky, 1988). Aiming a balance between anticipation and resilience should be the best BCM strategy for handling risks. For this however a process of continuous learning is required (Comfort, 1994). In the same spirit it was found that business continuity management and organizational resilience require not only learning, creative problem solving and adaptive innovation, but also many other aspects like e.g. proactive management and culture, improvement and refinement of assets, skills and technologies, data communication, preventative control, mindful action, etc. (Ruiz-Martin et al., 2018). The ability to forecast disruptions, to allocate resources of any kind to handle unexpected situations and to develop a system of actions involving the entire organization is increasing the effectiveness of a specific BCM strategy (Hollnagel et al, 2006). Thus, we propose the following third research hypothesis:

$H_{3}:$ There is a statistically significant correlation between technology and data communication required to carry out organization's critical activities and the business impact analysis.

The activities that sustain business impact analysis should relate the consequences of a disaster to the processes that support the enterprise's objectives and the proper delivery of its products or services. According to Faertes (2015), prior to introducing the business continuity management, each type of scenario has to be assigned a business impact analysis that refers to the process of assessing the maximum limit of time a certain activity could be disrupted without affecting other areas, the lowest level that a company can function and continues to fulfil its main objectives and the time limit through which the normal operations can be reinstated. The research implies the complexity of impact analysis process, starting with evaluating the consequences over the employee and community, the financial damages, the reputation and quality of services and not the least environmental damages. The loss associated with critical activities, namely, with great impact over the well-being of a company, needs to be recovered more rapidly than other type of losses (Faertes, 2015; Jingye and Takehiro, 2016). Therefore, a thorough estimation of impacts need to raise awareness of all stakeholders involved, suppliers and other partners. Hence, our forth research hypothesis is as follows:

$\mathrm{H}_{4}$ : There is a statistically significant correlation between supplies (raw materials, energy, services) and the business impact analysis. 


\section{Methodology}

This paper tests the prerequisites of the business impact analysis that an organization undertakes to build its business continuity management capability. The main goal of the paper is to discover what critical functions and resources are vital to business operations in a sample of Romanian small and medium-sized enterprises in order to maintain their core business and ensure the organization's resilience. A quantitative research was carried out among random sample companies in the capital city of Romania in the period October 2017 - January 2018, by employing an anonymous questionnaire-based survey. The research sample of respondents was selected randomly, but the responding companies had to meet certain conditions. The main criteria were that the companies are located in the capital city of Romania, are small or medium-sized and have a private-own capital. The data was collected through faceto-face interviews, for almost four month. The company representatives participating in the survey had to meet two specific criteria: hold a managerial position and have at least two years of seniority in the company. The questions were addressed in a structured and given order and discuss each key element of the business continuity management. As the data was collected based on direct interviews, respondents were offered clarifications as needed to ensure a high accuracy and relevance of their responses. The current paper interprets only partial data collected on questionnairebased survey. The critical resources and functions that the enterprise should take into consideration in undertaking a business impact analysis for business continuation are synthesized in Table 1 . These are further examined in the present paper.

Table 1. Research variables

\begin{tabular}{|l|l|}
\hline \multicolumn{1}{|c|}{ Critical resources } & \multicolumn{1}{c|}{ Critical activities/ functions } \\
\hline People (employees, contractors) & $\begin{array}{l}\text { Number of staff } \\
\text { Staffing level } \\
\end{array}$ \\
Skills / Level of expertize \\
\hline $\begin{array}{l}\text { Premises (places where the products } \\
\text { are processed/manufactured/stored, } \\
\text { the manufacturing equipment used) }\end{array}$ & Locations \\
Technology and data communication & Plant, machinery and other facilities \\
& IT \\
& Systems and means of voice and data \\
& communication \\
& Information \\
& Storage of information \\
\hline Supplies (raw materials, energy, & Priority suppliers/partners \\
services) & Key services tendered out \\
& Reciprocal arrangements \\
\hline
\end{tabular}

Source: Adapted based on ISO 22301:2012.

A total number of 146 completed questionnaires were collected. Twenty-seven questionnaires were excluded from analysis because of incomplete information or because they were filled in by organizations which didn't meet the research criteria. Hence, the current research interprets the responses collected from 119 respondents and the same number of companies. In order to assess the research results, descriptive statistics tools and linear regression analysis were used. 
Four research hypotheses $\left(\mathrm{H}_{1}, \mathrm{H}_{2}, \mathrm{H}_{3}\right.$, and $\left.\mathrm{H}_{4}\right)$ made the object of our analysis, defined on the basis of exploratory research, especially literary research, analysis and evaluation of the information and facts obtained (Figure 1). In the paper we offer empirical evidence on the following research questions: (1) Are staff number, staffing level and expertise, required to undertake organization's critical activities, vital to the business impact analysis?; (2) Do premises where the products are processed/ manufactured/ stored and the entire operational infrastructure affect the business impact analysis? (3) Are technology, data and communication, required to carry out organization's critical activities, vital the business impact analysis? (4) Are supplies critical to the business impact analysis? (5) Which one of those critical functions and resources has the most impact on business impact analysis for business continuity?

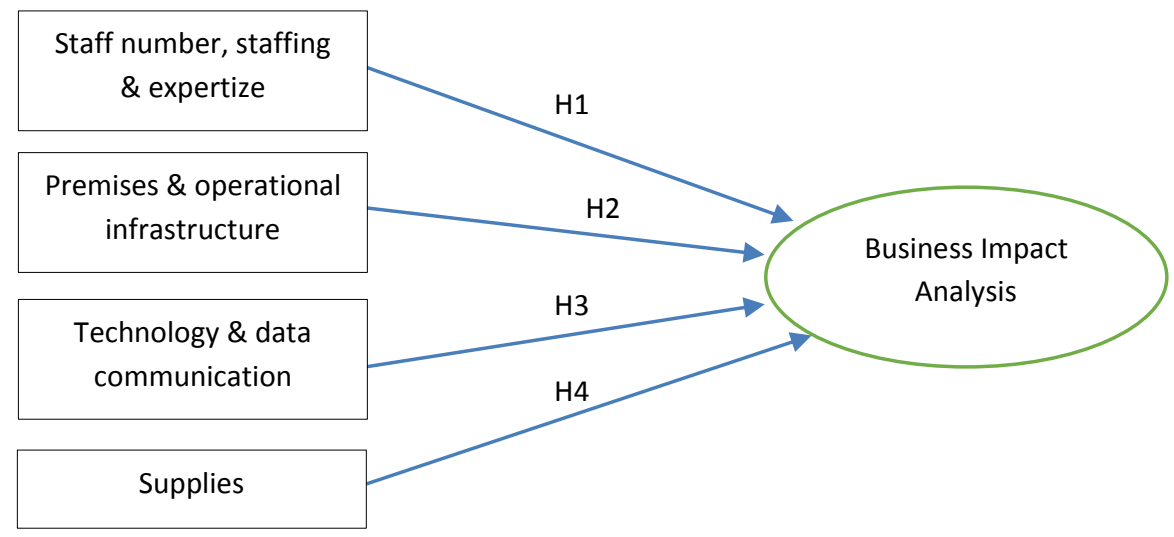

Figure 1. Research model

Source: Authors' own research

\section{Empirical results}

\section{The research sample}

The current research interprets the data collected from 119 small and middle-sized enterprises from the capital city of Romania. The sample of respondents included 53\% top managers, 33\% middle level managers and 14\% respondents holding other decisional roles in the company. There were 52\% males and $48 \%$ females in our sample, with an average seniority in the company of 9 years. Companies investigated are operating in different domains of activity, such as: IT, communications, personnel security, financial services, insurance, transport and distribution, import-export, food sector, textile industry, consulting, education and so forth.

\section{The regression analysis of the critical functions and resources on business impact analysis}

Business impact analysis helps with understanding which processes in the company are vital to its ongoing operations and to understand the impact the disruption of these processes would have on the business.

Multiple regression was conducted to determine the variance explained by the model (whether the variables selected were significant predictors of the business impact analysis) and the relative contribution of each of the predictors to the total variance explained. We used a linear regression to understand whether business 
impact analysis can be predicted based on the critical activities and resources of the organization -namely people (employees, contractors) required to carry out the critical activities, premises where the products are processed/manufactured/stored, including the manufacturing equipment used, technology and data communication which are vital to carry out the critical activities and supplies (raw materials, energy, services) which the organization depends on to undertake its critical activities.

Business impact analysis is a composite variable measured by taking into consideration all critical activities and resources (internal and external) required to maintain and resume the production of an enterprise's products. The multiple linear regression equation is as follows:

$$
\begin{aligned}
B I A=\beta_{0}+\beta_{1} N S+\beta_{2} S L+\beta_{3} L E+\beta_{4} L o c+\beta_{5} A P+\beta_{6} P M F+\beta_{7} I T \\
\\
+\beta_{8} S M V D C+\beta_{9} I n f o+\beta_{10} I S+\beta_{11} S P+\beta_{12} K S T+\beta_{13} R A+\varepsilon
\end{aligned}
$$

where BIA - Business impact analysis represents the dependent variable and the predictor variables are: NS - Number of staff; SL - Staffing level; LE - Level of expertize; Loc - Locations; AP - Alternative premises; PMF - Plant, machinery, other facilities; IT - Information technology; SMVDC - Systems and means of voice and data communication; Info - Information; IS - Information storage; SP - Suppliers and partners; KST - Key services tendered out; RA - Reciprocal arrangements.

To ensure that the linear regression can offer us a valid result we checked the data to make sure it can be actually analyzed using linear regression. Thus, we checked the Pearson's bivariate correlation (Table 2) and find that eight of our variables are significantly correlated at the 0.01 level (2-tailed), namely level of expertise, locations, alternative premises, plant, machinery, other facilities, IT, communication systems, information, and suppliers and partners. Five of our variables are significantly correlated with business impact analysis at the 0.05 level (2-tailed), more precisely number of staff $(r=0.196)$, staffing level $(r=210)$, information stored $(r=0.232)$, key services tendered out $(r=0.243)$, and reciprocal arrangements $(r=0.198)$. Some scholars recommend to remove from the analysis those variable with the $r$ Pearson correlation coefficients lower than 0.3 , as they will distort the regression results. We decided to exclude from our regression analysis those variable with a correlation coefficient $r<0.25$ and keep all the other variables in the model. Therefore, we conducted the regression analysis with the eight variables left. The new regression equation is as follows:

$$
\begin{gathered}
B I A=\beta_{0}+\beta_{1} L E+\beta_{2} L o c+\beta_{3} A P+\beta_{4} P M F+\beta_{5} I T+\beta_{6} S M V D C+\beta_{7} \text { Info } \\
+\beta_{8} S P+\varepsilon
\end{gathered}
$$

We further performed the regression analysis by using the Enter method of regression. The descriptive statistics and correlations between our variables are shown in Table 3. All the requested variables entered the model. 


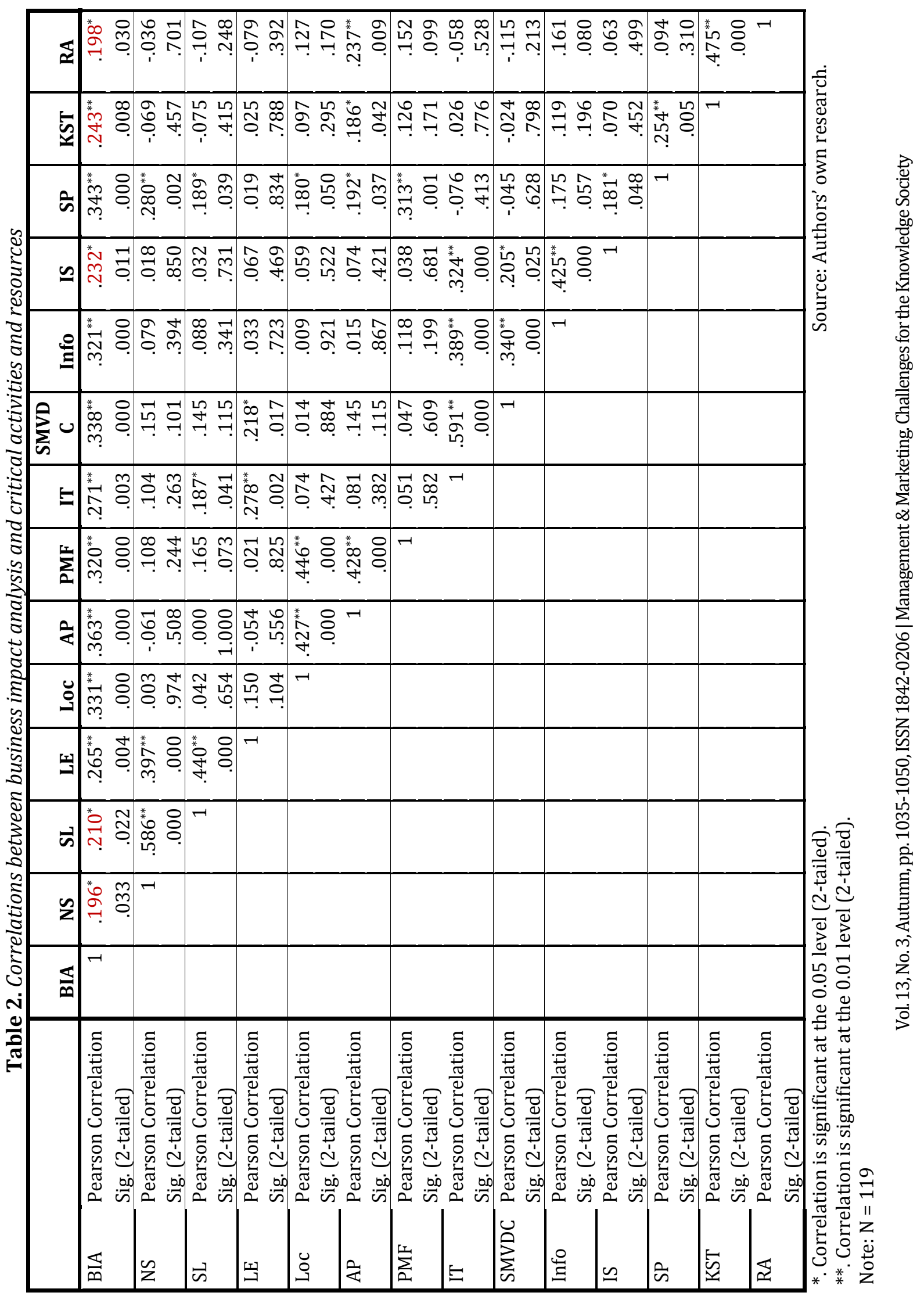


Table 3. Descriptive statistics and correlations

\begin{tabular}{|l|r|r|r|r|r|r|r|r|r|r|r|}
\hline & Mean & \multicolumn{1}{c|}{ SD } & BIA & \multicolumn{1}{c|}{ LE } & \multicolumn{1}{c|}{ Loc } & \multicolumn{1}{c|}{ AP } & \multicolumn{1}{c|}{ PMF } & \multicolumn{1}{c|}{ IT } & \multicolumn{1}{l|}{ SMVDC } & \multicolumn{1}{c|}{ Info } & \multicolumn{1}{c|}{ SP } \\
\hline BIA & 3.62 & .844 & 1.000 & $.265^{* *}$ & $.331^{* * *}$ & $.363^{* * *}$ & $.320^{* * *}$ & $.271^{* * *}$ & $.338^{* * *}$ & $.321^{* * *}$ & $.343^{* * *}$ \\
LE & 4.22 & 1.474 & & 1.000 & .150 & -.054 & .021 & $.278^{* * *}$ & $.218^{* *}$ & .033 & .019 \\
Loc & 3.98 & 1.707 & & & 1.000 & $.427^{* * *}$ & $.446^{* * *}$ & .074 & .014 & .009 & $.180^{* *}$ \\
AP & 2.92 & 2.009 & & & & 1.000 & $.428^{* * *}$ & .081 & .145 & .015 & $.192^{* *}$ \\
PMF & 3.84 & 1.722 & & & & & 1.000 & .051 & .047 & .118 & $.313^{* * *}$ \\
IT & 4.12 & 1.569 & & & & & & 1.000 & $.591^{* * *}$ & $.389^{* * *}$ & -.076 \\
SMVDC & 3.88 & 1.743 & & & & & & & 1.000 & $.340^{* * *}$ & -.045 \\
Info & 3.99 & 1.613 & & & & & & & & 1.000 & $.175^{* *}$ \\
SP & 4.28 & 1.420 & & & & & & & & & 1.000 \\
\hline
\end{tabular}

*. Correlation is significant at the 0.05 level (1-tailed).

Source: Authors' own research.

**. Correlation is significant at the 0.01 level (1-tailed).

***. Correlation is significant at the 0.001 level (1-tailed).

Note: N=119; LE - Level of expertize; Loc - Locations; AP - Alternative premises; PMF - Plant, machinery, other facilities; IT - Information technology; SMVDC - Systems and means of voice and data communication; Info - Information; IS - Information stored; SP - Suppliers and partners;

Model summary in Table 4 shows that our influencing variables predicts $40.5 \%$ of the variation in the business impact analysis. The Durbin-Watson $d=1.924$, which is between the two critical values of $1.5<\mathrm{d}<2.5$, tells us that there is no first order linear auto-correlation in our multiple linear regression data and model is a good fit.

Table 4. Model summary ${ }^{b}$

\begin{tabular}{|c|c|c|c|c|c|c|c|c|c|c|}
\hline \multirow[b]{2}{*}{ Model } & \multirow[b]{2}{*}{$\mathbf{R}$} & \multirow[b]{2}{*}{$\mathbf{R}^{2}$} & \multirow[b]{2}{*}{$\begin{array}{c}\text { Adjusted } \\
\mathbf{R}^{2}\end{array}$} & \multirow[b]{2}{*}{$\begin{array}{l}\text { SE of the } \\
\text { Estimate }\end{array}$} & \multicolumn{5}{|c|}{ Change Statistics } & \multirow[b]{2}{*}{$\begin{array}{l}\text { Durbin- } \\
\text { Watson }\end{array}$} \\
\hline & & & & & $\Delta \mathrm{R}^{2}$ & $\Delta \mathbf{F}$ & df1 & df2 & $\begin{array}{c}\text { Sig. F } \\
\text { Change }\end{array}$ & \\
\hline 1 & $.636^{\mathrm{a}}$ & .405 & .362 & .674 & .405 & 9.352 & 8 & 110 & .000 & 1.924 \\
\hline
\end{tabular}

a. Predictors: (Constant), SP, LE, Info, AP, SMVDC, Loc, PMF, IT

b. Dependent Variable: BIA

The ANOVA results in Table 5 show that all our variables are significant predictors of the business impact analysis $(\mathrm{F}=9.352, \mathrm{p}<0.001)$, and that the model is a good fit.

Table 5. ANOVA ${ }^{a}$

\begin{tabular}{|ll|r|r|r|r|r|}
\hline & \multicolumn{1}{|c|}{$\begin{array}{c}\text { Sum of } \\
\text { Model }\end{array}$} & \multicolumn{1}{c|}{ Squares } & Mean Square & F & \multicolumn{1}{c|}{ Sig. } \\
\hline 1 & Regression & 33.997 & 8 & 4.250 & 9.352 & $.000^{\mathrm{b}}$ \\
& Residual & 49.986 & 110 & .454 & & \\
Total & 83.983 & 118 & & & \\
\hline
\end{tabular}

Source: Authors' own research.

a. Dependent Variable: BIA

b. Predictors: (Constant), SP, LE, Info, AP, SMVDC, Loc, PMF, IT

Vol. 13, No. 3, Autumn, pp. 1035-1050, ISSN 1842-0206 | Management \& Marketing. Challenges for the Knowledge Society 
The coefficients (Table 6) show that suppliers and partners (SP) is significant $(\mathrm{p}<0.01)$ and positive predictor of business impact analysis (BIA) and level of expertize (LE), alternative premises (AP), systems and means of voice and data communication (SMVDC) and information (Info) are also significant $(\mathrm{p}<0.05)$ and positive predictors of the BIA. In our regression model SP $(b=0.138), L E(b=0.113)$ and Info $(b=0.100)$ are the strongest predictors of the BIA. Thus, a 1-unit increase in identification of priority suppliers/partners whom the organization depends on to undertake its critical activities will result in 0.138 unit increase in the relevance of business impact analysis. Also, a 1-unit increase in identification of skills and level of expertise required to undertake the critical activities will result in 0.113 unit increase in the accuracy of business impact analysis and 1-unit increase in documentation of the information which is essential to carry out organization's critical activities will result in 0.100 unit increase in the relevance of business impact analysis. Our regression analysis results also show that locations, plant, machinery and other facilities and IT are not statistically significant predictors of the business impact analysis. Therefore, each one of our research hypotheses $\mathrm{H}_{1} \div \mathrm{H}_{4}$ has been only partially confirmed. As such, for our sample companies, concerning "people" as critical resource, the enterprise should give priority to identifying the level of expertise required to carry out its critical activities. Regarding "premises" as critical resource, the enterprise should give priority to identifying alternative premises it has. Concerning "technology and data" as critical resource, the enterprise should give priority to identifying systems and means of voice and data communication required to carry out its critical activities. Finally, in what regards "supplies" as critical resource, the enterprise should give priority to identifying its priority suppliers/partners whom it depends on to undertake its critical activities.

Table 6. Coefficients ${ }^{a}$

\begin{tabular}{|c|c|c|c|c|c|c|c|c|c|}
\hline \multirow[b]{2}{*}{ Model } & \multicolumn{2}{|c|}{$\begin{array}{c}\text { Unstandard. } \\
\text { Coeff. }\end{array}$} & \multirow{2}{*}{$\begin{array}{c}\begin{array}{c}\text { Standard. } \\
\text { Coeff. }\end{array} \\
\text { Beta } \\
\end{array}$} & \multirow[b]{2}{*}{$\mathbf{t}$} & \multirow[b]{2}{*}{ Sig. } & \multicolumn{2}{|c|}{$\begin{array}{c}95.0 \% \\
\text { Confidence } \\
\text { Interval for B }\end{array}$} & \multicolumn{2}{|c|}{$\begin{array}{c}\text { Collinearity } \\
\text { Statistics }\end{array}$} \\
\hline & B & $\begin{array}{c}\text { Std. } \\
\text { Error }\end{array}$ & & & & $\begin{array}{l}\text { Lower } \\
\text { Bound }\end{array}$ & $\begin{array}{l}\text { Upper } \\
\text { Bound }\end{array}$ & $\begin{array}{l}\text { Tole- } \\
\text { rance }\end{array}$ & VIF \\
\hline 1 (Constant) & 1.118 & .319 & & 3.508 & .001 & .486 & 1.749 & & \\
\hline LE & .113 & .045 & .197 & 2.490 & .014 & .023 & .203 & .862 & 1.160 \\
\hline Loc & .068 & .044 & .137 & 1.560 & .122 & -.018 & .154 & .698 & 1.433 \\
\hline $\mathrm{AP}$ & .089 & .037 & .213 & 2.425 & .017 & .016 & .163 & .701 & 1.427 \\
\hline PMF & .029 & .044 & .058 & .655 & .514 & -.058 & .115 & .685 & 1.461 \\
\hline IT & .006 & .052 & .012 & .120 & .905 & -.097 & .110 & .571 & 1.751 \\
\hline SMVDC & .096 & .046 & .198 & 2.107 & .037 & .006 & .186 & .610 & 1.639 \\
\hline Info & .100 & .044 & .191 & 2.271 & .025 & .013 & .187 & .765 & 1.306 \\
\hline SP & .138 & .048 & .232 & 2.893 & .005 & .043 & .232 & .843 & 1.186 \\
\hline
\end{tabular}

a. Dependent Variable: BIA

The standardized beta values indicate that SP $(\beta=0.232, \mathrm{t}(119)=2.893)$, AP $(\beta=0.213, \quad \mathrm{t}(119)=2.425), \quad \mathrm{SMDVC} \quad(\beta=0.198, \quad \mathrm{t}(119)=2.107), \quad \mathrm{LE} \quad(\beta=0.197$, $\mathrm{t}(119)=2.490)$ and Info $(\beta=0.191, \mathrm{t}(119)=2.271)$ have the most impact in the model in this order. The values of VIF, which stands for variance inflation factor, close to 1 or 2 
indicate that there is no collinearity found between independent variables. The more the VIF increases, the less reliable the regression results are going to be. Thus, in our regression model all predictor variables can independently predict the value of the dependent variable.

\section{Conclusion}

In the current environment, where threats and disruptions may have significant consequences for companies' performance and future, one of the main goals for organizations is considered to be the development of business continuity plans, as well as proactive management and readiness to handle incidents of any kind. The whole process starts with a good understanding of organization, followed by determination of the business continuity management strategy, development and implementation of the BCM response, exercise, preservation and review of the BCM arrangements, and concluding with embedding the BCM in the organization's culture. Business impact analysis is the most relevant element in understanding how an organization functions, together with risk assessment.

The paper investigates the prerequisites of the organization's business impact analysis necessary to build its business continuity management capability and ensure organization's resilience. It was meant to discover those critical functions and resources which are vital to core business operations in a sample of small and medium-sized enterprises from a certain geographic area in Romania, in order to maintain their core products and services and ensure business continuation.

Overall, our research findings indicate that, in undertaking business impact analysis for business continuity, it is vital for enterprises to identify the skills and level of expertise required from staff to carry out organization's critical activities. Moreover, it is critical for companies to identify alternative premises and systems and means of voice and data communication as well as the priority suppliers and partners whom they depend on to undertake their critical activities.

The present study reveals a positive and strong correlation between the staff's expertize and level of knowledge and business impact analysis, training and simulation sessions being the key argument in sustaining a reliable business continuity plan. This was also confirmed by other similar researches conducted more recently (Baba et al. 2013; Tucker, 2016; Kato and Charoenrat, 2018). The human factor, staff, managers, administrators and local authorities are strong predictors for undertaking a well-documented business impact analysis, although there are studies which confirm the importance of assessing the value and location of critical assets and resources in identifying potential gaps, risks and disruptions (Blos et al., 2015; Asnar and Giorgini, 2018). The ability of leveraging technology and information, as well as supplies network represent strong positive predictors as well for business continuity and resilience management in case of disasters or unexpected events. This finding is supported by other recent studies like the one conducted recently by Tibay et al. (2017). Also, accessibility to alternative premises, necessary to relocate operations in the event of a disaster, is another strong predictor of business impact analysis to build strong business continuity capability. The Business Continuity Management Institute (https://www.bcm-institute.org/) from Singapore names the need to have alternative premises to relocate operations to another site during a disaster as one of the first 
priority strategy for recovery of critical business functions. This comes as a good support for our research findings.

Failure to support vital business functions after a disaster can be fatal for the organization. That is why it is very important to carefully go through each stage of business impact analysis and disaster development process, from preventive and mitigation actions, to preparation and responsiveness and finally to rehabilitation and recovery. It is also decisive to involve the senior management but also department's manager in the development of BCM strategy, to involve the whole staff by having a resilience culture and proper training in place.

From theoretical perspective, the present study contributes to the literature by providing empirical evidence on the critical prerequisites of a sound business impact analysis for building strong business continuity and ensuring organization's resilience. From practical point of view, it offers new insights to companies meant to generate a better understanding of current practices of undertaking a business impact analysis for business continuity in their organizations.

Our study is not without limitation. First limitation refers to the geographic coverage of data, the sample size and range of activities covered by the companies surveyed. Thus, the interpretation of our results requires caution and may not be extended for all types of companies and all domains of activity. Secondly, some questionnaires (14\%) were filled in by persons holding different decision-making roles in the company, who might not have a complete understanding of the business continuity management in their organization and, therefore, their responses might be inaccurate. Finally, future research is needed to enlarge this study, possibly to offer a wider, national or cross-country investigation, including more data about companies from all public, private and non-governmental sector and different domains of activity.

\section{References}

Asnar, Y. and Giorgini, P. (2008), "Analyzing business continuity through a multi- layer model”, in M. Dumas, M. Reichert, and M.-C. Shan (Eds.): BPM 2008, LNCS 5240, pp. 212-227, Springer-Verlag: Berlin, Heidelberg.

Baba, H., Adachi, I., Takabayashi, H., Nagatomo, N., Nakasone, S., Matsumoto, H. and Shimano, T. (2013), "Introductory study on disaster risk assessment and area business continuity planning in industry agglomerated areas in the ASEAN", Journal of Integrated Disaster Management, Vol. 3, No 2, pp. 184-195.

Baba, H., Watanabe, T., Nagaishi, M. and Matsumoto, H. (2014), "Area business continuity management, a new opportunity for building economic resilience", Procedia Economic and Finance, Vol. 18, pp. 296-303.

Bjerga, T. and Aven, T. (2016), "Some perspectives on risk management: A security case study from the oil and gas industry", in Proceedings of the Institution of Mechanical Engineers, Part O: Journal of Risk and Reliability, Vol. June, pp. 114.

Blos, M.F., Hoeflich, S.L. and Miyagi, P.E. (2015), “A general supply continuity management framework", Procedia Computer Science, Vol. 55, pp. 1160-1164.

Cerullo, V. and Cerullo, M.J. (2004), "Business continuity planning: a comprehensive approach", Information Systems Management, Vol. 21, No. 3, pp. 70-78. 
Charoenrat, T. and Harvie, C. (2014), "The efficiency of SMEs in Thai manufacturing: a stochastic frontier analysis", Economic Model, Vol. 43, pp. 372-393.

Comfort, L.K. (1994), "Risk and resilience: International learning following the Northridge Earthquake of January 17, 1994", Journal of Contingencies and Crisis Management, Vol. 2, No. 3, pp. 174-188.

Faertes, D. (2015), "Reliability of supply chains and business continuity management", Procedia Computer Science, Vol. 55, pp. 1400-1409.

Fischbacher-Smith, D. (2017), "When organizational effectiveness fails: Business continuity management and the paradox of performance", Journal of Organizational Effectiveness: People and Performance, Vol. 4, No. 1, pp. 89-107.

Giacchero, A., Giordano, F. and Schiraldi, M.M. (2013), "From business continuity to design of critical infrastructures: ensuring the proper resilience level to datacenters", International Journal of Engineering and Technology, Vol. 5, No. 4, pp. 3544-3553.

Hollnagel, E., Woods, D.D. and Leveson, N. (2006), “Resilience Engineering - Concepts and Precepts." Ashgate Publishing: Aldershot, pp. 9-17.

International Organization for Standardization (2012), "ISO 22301 Societal security business continuity management systems-requirements", Switzerland: Geneva.

Jingye, L. and Takehiro, T. (2016), "Practical process for introducing smart business continuity management of smart city in Japan", Procedia Engineering, Vol. 146, pp. 288-295.

Kato, M. and Charoenrat, T. (2018), "Business continuity management of small and medium sized enterprises: Evidence from Thailand", International Journal of Disaster Risk Reduction, Vol. 27, pp. 577-587.

Maruya, H. and Torayashiki, T. (2017), "Damage of enterprises and their business continuity in the 2016 Kumamoto earthquake", Journal of Disaster Research, Vol. 12, Special Issue, pp. 688-695.

Mcilwee, P. (2013), "Business continuity management", in Penuel, K.B., Statler, M. and Hagen, R. (Eds), Encyclopedia of Crisis Management, Sage Publications: Thousand Oaks, CA, pp. 74-76.

Ota, S. (2011), "An empirical study of bankruptcy and turnaround in post-March 11 Northeastern Japan: Corporate risk management for natural disasters", Management Journal, Vol. 4, pp. 23-44.

Păunescu C. (2017), "How prepared are small and medium sized companies for Business Continuity Management?" Quality. Access to Success, Vol. 18, No. 161, pp. 43-48.

Ruiz-Martin, C., López-Paredes, A. and Wainer, G., (2018), “What we know and do not know about organizational resilience", International Journal of Production Management and Engineering, Vol. 6, No. 1, pp. 11-28.

Speight, P. (2011), "Business continuity", Journal of Applied Security Research, Vol. 6, No. 4, pp. 529-554.

Tan, T. and Takakuwa, S. (2011), "Use of simulation in a factory for business continuity planning", International Journal of Operational Risk, Vol. 2, No. 4, pp. 79-96. 
Tibay, V., Miller, J., Chang- Richards, A., Egbelakin, T., Seville, E. and Wilkinson, S. (2017),“Business resilience: A study of Auckland hospitality sector”, Procedia Engineering, Vol. 212, pp. 1217-1224.

Tracey, S., O'Sullivan, T.L., Lane, D.E., Guy, E. and Courtemache, J. (2017), "Promoting resilience using an asset-based approach to business continuity planning", Sage Journals, Vol. 7, No. 2, pp. 1-15.

Tucker, E. (2015), "Business continuity from preparedness to recovery. A standards based approach", Elsevier: Amsterdam.

Wildavsky, A. (1988), "Searching for safety", New Brunswick, NJ: Transaction Press.

Zeng, Z. and Zio, E. (2017), "An integrated modeling framework for quantitative business continuity assessment", Process Safety and Environmental Protection, Vol. 106, pp. 76-88. 